\title{
AS LIBERDADES INFORMATIVAS E A PARTICIPAÇÃO PRIVADA DOS MEIOS DE COMUNICAÇÃO NO PROCESSO DE DESENVOLVIMENTO DEMOCRÁTICO: UM PARALELO ENTRE OS MONOPÓLIOS ECONÔMICOS E OS INTERESSES SOCIAIS
}

\author{
THE INFORMATIVE FREEDOMS AND \\ PRIVATE PARTICIPATION OF THE MEDIA IN \\ DEMOCRATIC DEVELOPMENT PROCESS: A \\ PARALLEL BETWEEN MONOPOLY ECONOMIC \\ AND SOCIAL INTERESTS
}

Jorge Renato dos Reis ${ }^{*}$ Felipe da Veiga Dias ${ }^{* *}$

\section{RESUMO}

As liberdades informativas (comunicativas) foram protegidas a fim de resguardar a livre difusão do pensamento e da informação, seguindo os ideais constitucionais (baseados na dignidade humana), os quais, assimilados também pelo direito privado, uniram questões sociais a interesses econômicos. Destarte, os chamados poderes privados,

\footnotetext{
* Pós-Doutor em Direito pela Universidade de Salerno-Itália, Professor-Coordenador do Programa de Pós-graduação em Direito - Mestrado e Doutorado da UNISC. Santa Cruz do Sul - RS. Brasil. Coordenador dos Projetos "Políticas públicas de educação para o consumo" e "O direito de autor no constitucionalismo contemporâneo: um estudo comparado Brasil x Uruguai". Coordenador dos Grupos de Estudos e Pesquisas (CNPQ) “Intersecções jurídicas entre o público e o privado" e "Direito de Autor". Contato: jreis@viavale.com.br

** Doutorando e Mestre em Direito pela Universidade de Santa Cruz do Sul (UNISC). Especialista em Direitos Fundamentais e Constitucionalização do Direito - PUC/RS. Santa Cruz do Sul - RS. Brasil. Integrante dos Grupos de Estudos “Intersecções jurídicas entre o público e privado" e "Direito de Autor", coordenados pelo Prof. Jorge Renato dos Reis. Participante dos projetos de pesquisa "O direito de autor no constitucionalismo contemporâneo: um estudo comparado Brasil x Uruguai" e "Políticas públicas de educação para o consumo". Bolsista CAPES. Advogado. Contato: felipevdias@gmail.com
} 
como os monopólios informativos, são práticas a serem combatidas, por incompatibilizarem-se com o modelo constitucional democrático. Assim, defende-se perspectiva contrária a tais abusos de poder, haja vista que as liberdades informativas acabam tolhidas pela vedação da pluralidade imposta por tais monopólios; portanto, preza-se pelo modelo social esculpido pela Constituição, sustentada em ideais de equidade e justiça.

Palavras-chave: Liberdades informativas. Função social. Monopólios.

\begin{abstract}
The freedom of information (communication) were protected in order to safeguard the free dissemination of ideas and information, following the constitutional ideals (based on human dignity), which, also assimilated the private law, joined social issues to economic interests. Thus, the so-called private powers, such as monopolies informational practices are to be fought for is inconsistent with the constitutional model of democracy. Thus, it is argued perspective contrary to such abuses of power, given that the information freedoms curtailed by the end of the plurality seal imposed by such monopolies, so it is appreciated by the social model carved by the Constitution, supported by the ideals of fairness and justice.
\end{abstract}

Keywords: Freedoms informative. Social function. Monopolies.

\title{
INTRODUÇÃO
}

O panorama sócio-jurídico nacional transformou-se nas últimas décadas, muito em consequência do novo marco constitucional de 1988 (Estado Democrático de Direito), o qual buscava trazer nova luz não somente ao Direito, mas a sociedade como um todo. O resplandecer desse novo horizonte alterou significativamente as bases ideológicas que sustentavam o alicerce positivista, dando margem a anseios e necessidades sociais, tais como a organização principiológica, a hermenêutica constitucional, a efetivação dos direitos fundamentais, dentre outras.

Nessa senda também se encontra o respeito às liberdades expressivas, com seu contributo à formação de um modelo social 
democrático e plural, de maneira que a sua efetivação e garantia são inerentes à preservação desse novo perfil constitucional. Entretanto, há nuances na proteção comunicativa que não parecem evidentes em uma observação superficial, já que a atividade neste caso é realizada por entes privados, ou seja, expostos às exigências de mercado e outras pressões, mas ao mesmo tempo são exercícios de direitos fundamentais preciosos à coletividade.

Diante disso existe a imperiosidade de atenção por parte do Estado nessa atividade, tendo em vista o seu valor dentro do modelo democrático, mas, sem, contudo, exceder-se com intervenções desnecessárias. Refere-se à necessidade de vigília sob tais interesses, visto que se percebeu atualmente a existência de grandes poderes nas mãos de órgãos privados, os quais por vezes são mais influentes que o próprio Estado e, por isso, a ocorrência de grandes monopólios de empresas no campo das comunicações é vista como prejudicial à pluralidade informativa e democrática.

A fim de impedir a sobreposição particular sobre a coletividade e os direitos fundamentais, tem-se a função social, a qual é a outra face do dilema constitucional, pois se precisa de uma imprensa livre, atuante, executando sua função social e, ao mesmo tempo, devem-se vedar os monopólios da atividade. Esse paralelo ponderativo entre questões econômicas e sócio-democráticas é árduo e, durante esse artigo, pretende-se debruçar-se sobre tal problemática, para ao final apontar o entendimento mais adequado, na perspectiva dos autores, à visão protetora de direitos fundamentais, harmonizada com o direito privado.

\section{AS LIBERDADES EXPRESSIVAS NA SOCIEDADE DEMOCRÁTICA}

A perspectiva inaugurada pela nova Constituição veio alicerçada por uma forte estrutura axiológica, tendo como base angular a dignidade humana (fundamento da República) ${ }^{1}$; esse (direito) princípio é o núcleo do qual emanam variações diversas, haja vista que a partir dele se deduzem os demais princípios constitucionais e direitos fundamentais ${ }^{2}$. A dedução da conexão aludida é explicada pelo próprio grau de abstração da dignidade da pessoa humana, já que para reduzir o seu 
nível de imaterialidade, utiliza-se de suas ramificações para fortalecer determinados sentidos específicos de atuação do (direito) princípio, bem como se impede a banalização do seu uso.

Apesar da dificuldade conceitual, isso não impede que se traga uma compreensão mínima do princípio da dignidade humana, focada em oportunizar um norte na leitura do presente artigo; mais precisamente, compreende-se o citado princípio como fundamento protetor do ser humano em sua individualidade, externando uma posição de respeito e, ao mesmo tempo, entendendo o seu caráter único em sua existência, afastando qualquer tratamento do homem como objeto (influência da concepção kantiana). ${ }^{3}$

Apresentando-se no sentido especializado de materialização da dignidade humana, tem-se a preocupação com as manifestações do homem, ou seja, as palavras por ele proferidas em todo o seu poder, comumente conhecida como liberdade de expressão. Esta esfera de liberdade visa uma proteção ampla, defendendo opiniões, juízos, idéias variadas, ressalvadas situações singulares, como por exemplo, a incitação à violência.

A partir da sustentação da liberdade de expressão, particularizam-se outros direitos fundamentais, tais como a liberdade de imprensa e informação, ambas originárias da proteção comunicativa das expressões humanas ${ }^{4}$. Nas duas facetas citadas, estruturam-se construções detalhadas sobre cada uma delas, ensejando a exposição de alguns desses traços para aprofundar o debate.

Tomando-se inicialmente a liberdade de imprensa, define-se o seu aspecto diferencial em relação à liberdade de expressão como sendo o seu meio ou forma de transmissão das notícias e informações. Apesar de estabelecer uma relação simbiótica com as outras liberdades (expressão e informação) ${ }^{5}$, a doutrina aponta singularidades no exercício desse direito fundamental. Demonstração da última alusão são os deveres decorrentes da atividade comunicativa da imprensa, denominados de: dever geral de cuidado, dever de veracidade e o dever de pertinência.

Esses deveres conectados à liberdade de imprensa pretendem impor ordem ao pleno uso desse direito, considerando-se que req- 
uisitos como cuidado (pregando a prudência jornalística e o respeito para com os demais seres humanos) ou a pertinência (nexo causal entre o fato e a notícia veiculada) são importantes para manutenção da higidez informativa à população. Dentre as subdivisões mencionadas acima, importante frisar o dever de veracidade (este se repetindo na estrutura do direito à informação), pois significa o compromisso com a boa-fé, já que se toleram equívocos na atividade profissional desde que se deem na tentativa de adimplir com o compromisso informativo e social da liberdade de imprensa ${ }^{6}$. Isso significa que o comunicador se compromete com a busca da verdade, obedecendo a padrões éticos e constitucionais na realização de sua atividade.

Ademais, a imposição da veracidade dentre os deveres proporciona outro entendimento, no sentido de que não está autorizada a mentira na atividade jornalística (fundamentando institutos como o direito de resposta $)^{7}$. Além de todos esses alicerces da liberdade de imprensa (deveres e o resguardo constitucional expresso) ${ }^{8}$, existem outros fatores a contribuírem na equação constitucionalizada para sociedade brasileira, porém serão analisados conjuntamente após a explanação sobre o direito à informação.

A segunda ramificação da liberdade de expressão, conhecida como direito à informação, tem geralmente seus traços delineados pelas noções de um direito a ser informado e a ter acesso às informações, ou seja, esse direito fundamental costuma ser dualizado no atendimento mínimo à população e na facilitação da mesma buscar o conhecimento9 . Evidentemente encontram-se construções na doutrina com uma maior variedade de subdivisões, no entanto, entende-se como sendo as principais aquelas já referidas ${ }^{10}$.

Igualmente à liberdade de imprensa, o direito à informação também recebe proteção constitucional positivada e, de maneira semelhante, quando se aborda o direito de informar há exigência de veracidade e clareza na prestação de tais informações ${ }^{11}$, percebendose o grau de importância do exercício dos direitos fundamentais em foco neste estudo por parte dos meios de comunicação, mesmo que neste caso caiba mencionar o requisito da veracidade como sendo de ordem subjetiva, ou seja, adotando-se uma conduta profissional pautada pela boa-fé ${ }^{12}$. 
As construções dos direitos fundamentais à liberdade de imprensa e informação expostas apresentam o teor da profundidade teórica desses interesses constitucionais, justificando-se as preocupações com a sua efetividade e defesa ante o componente histórico nacional, visto que antes do recente período democrático, galgado no marco constitucional de 1988, viveu-se no país um período ditatorial, o qual além reduzir o valor da Constituição ${ }^{13}$, oprimiu as expressões públicas e privadas, em claro antagonismo ao pensamento hodierno.

Soma-se ao componente histórico a dificuldade mencionada anteriormente de ponderar os interesses privados, de cunho econômico (exigências mercadológicas), com as questões públicas (coletivas), concretizando a função social por meio de uma imprensa livre e responsável. A complexidade inserida nessa correlação é recrudescida pelo componente da democracia ${ }^{14}$, cujos pressupostos reclamam uma sociedade que tem por dever a disseminação plural da informação para acrescentar conhecimento e cultura na formação da opinião pública, bem como da própria personalidade humana, sem nenhuma espécie de censura prévia ${ }^{15}$.

Especificar o âmbito que se deseja aplacar acerca da sociedade democrática é forçoso, tendo em vista que a ótica a ser relatada é ampla, mas não se atendo às espécies de democracia, tampouco às discussões sobre a sua conceituação.

Ante a exposição da relevância das liberdades informativas (ou comunicativas) no contexto social, democrático e jurídico-constitucional, compreende-se a importância de suas reformulações na ótica privada, já que os meios de comunicação que exercem efetivamente tais direitos fundamentais, apesar dos deveres sociais e democráticos, ainda vinculam-se a preocupações econômicas. $\mathrm{O}$ temor diante do poder acumulado por tais ferramentas informativas é considerável, haja vista a realização, por vezes, de uma função de "controle externo" das atividades dos demais Poderes estatais. Porém, reflete-se sobre o equivocado entendimento dessas liberdades como direitos individuais, pertencendo aos profissionais da imprensa, pois esses direitos apesar de exercidos por órgãos e indivíduos não são próprios, ou seja, eles pertencem à coletividade. ${ }^{16}$

Apresentados os traços dos direitos fundamentais em apreço, vinculados a um modelo de sociedade democrática, constata-se, por- 
tanto, a elevada importância do seu exercício livre e responsável para o desenvolvimento nacional. Dito isso, a etapa seguinte desse estudo é analisar o campo jurídico privado e os riscos que ele oferece a este novo perfil constitucional, de justiça e equidade entre os cidadãos.

\section{AS NOVAS RELAÇÕES PRIVADAS - OS MONO- PÓLIOS INFORMATIVOS E A FUNÇÃO SOCIAL}

A força constitucional manifestou-se em todo o ordenamento jurídico (irradiação de efeitos), e o caso do direito privado não foi diferente, obviamente com as suas etapas, visto que essa parcela do Direito teve vida própria e evolução apartada do direito público durante largo período da história. Todavia, com o advento da Constituição e da sua base valorativa, alterou-se o próprio centro gravitacional do direito privado, de maneira que a partir dali dever-se-ia pautar toda uma remodelação, teórica e prática, visando alterar mais do que as relações particulares, mas sim a própria visão econômica. ${ }^{17}$

O fenômeno da constitucionalização do direito privado, ${ }^{18}$ conforme ficou denominado, trouxe novo corpo a conceitos jurídico-civis, enaltecendo a importância hermenêutica do intérprete nas relações entre particulares. Sob a égide desse novo prisma constitucional, institutos como a propriedade, os contratos, assim como as empresas tiveram sua própria concepção invadida pela função social, buscando harmonizar as relações entre a autonomia privada e os demais interesses constitucionais. ${ }^{19}$

As observações acima induzem a algumas considerações, dentre elas: a) a irradiação de efeitos levou o direito privado a abandonar o seu antigo perfil puramente patrimonialista; b) estando as empresas compreendidas dentro de um ideal de cumprimento de função social, logo os meios de comunicação também se encontram nessa mesma situação, tendo em vista que são entes privados; c) os meios de comunicação devem adimplir com a sua função social, a fim de respeitar os direitos fundamentais por eles exercidos, ponderando questões econômicas e sociais para ofertar um desenvolvimento democrático adequado à nação.

Há aqui a necessidade de ressalva do ponto de vista econômico, pois embora o Direito venha tentando cumprir sua parte, a modificação 
do panorama para uma perspectiva mais ampla (que inclua desenvolvimento econômico e democrático, por exemplo), independe de suas forças; embora o Estado brasileiro pense nesse sentido, hoje pouco se faz para modificar a forma de desenvolvimento econômico e o próprio gerenciamento das camadas trabalhadoras. A nova visão de alguns estudiosos para a economia ${ }^{20}$ ainda tarda em gerar efeitos concretos nas relações privadas; isso se alega sob uma ótica global, mas frisa-se que o componente ético já se encontra germinando no texto constitucional.

Não desejando fugir da temática, aludiu-se o entendimento supramencionado como conhecimento combinado, ou seja, de nada adianta observar um problema complexo nas relações privadas a partir do olhar jurídico simples, quando é necessário agregar e estender o raio de visão para propor soluções.

Assim, retomando os trilhos do direito privado, merece atenção o tema dos poderes privados ${ }^{21}$, os quais são a demonstração de uma nova realidade econômica, na qual entes particulares são capazes de deter grandes poderes, ocasionando a verticalização da relação privada, assemelhando-se a um efeito anteriormente visto somente na relação Estado-cidadão ${ }^{22}$. Essa demonstração de poder por parte de particulares reforça a tese dos defensores dos efeitos dos direitos fundamentais no campo privado, já que inexiste nesses casos equilíbrio entre as partes e, portanto, há iminência de lesões aos direitos do indivíduo.

Prosseguindo nesse raciocínio, aponta-se como uma demonstração dos poderes privados os chamados monopólios da informação; nestas situações as empresas de comunicação, não bastasse a detenção de elevado poder econômico, ainda comportam grandes parcelas das ferramentas informativas, podendo impor uma "ditadura informativa". Conforme mencionado anteriormente, essa espécie de conduta por parte de órgãos privados antagoniza com os fundamentos axiológicos trazidos na Constituição, além de ser incompatível com uma sociedade democrática e pluralista ${ }^{23}$. Portanto, uma situação inconstitucional do ponto de vista que não haveria resguardo adequado dos direitos fundamentais, tampouco se proporcionaria a construção digna da personalidade humana restringindo-se o acesso à informação e ao conhecimento ${ }^{24}$.

A restrição a um mínimo de variação nas manifestações de opinião constrói uma nação alienada (opinião pública pobre), e tendo 
em vista os prejuízos possibilitados pela unicidade informativa é que não se podem aceitar tais monopólios no caminho de um crescimento social e democrático. Dessa forma, o exercício abusivo do poder econômico, especificamente nos monopólios informativos, é uma prática antagônica aos interesses constitucionais, podendo ser vista como antidemocrática. $^{25}$

Entretanto, existem opiniões contrárias, não no sentido de apoio aos monopólios informativos, mas que negam a sua existência, sendo tal posicionamento encontrado na doutrina norte-americana aqui representada nas palavras de Owen Fiss ${ }^{26}$ :

Algunos de quienes imaginaron un mayor papel para el Estado hablaron del <<poder monopólico>>. Invocaron estadísticas sobre el número de ciudades en América que no tienen periódicos o que sólo tienen uno - un número espantosamente alto de ciudades -, e hicieron referencia a la posición privilegiada de las tres grandes cadenas para captar la atención de la audiencia. Siempre encontré poco convincente esta manera de analizar la cuestión, no porque yo vislumbrara en el horizonte el cable o las nuevas tenologías de la información, sino porque quienes expresaron sus argumentos en términos de poder monopólico concebían el mercado de un modo demasiado estrecho. A efectos constitucionales, el mercado relevante es el informativo, el ámbito a partir del cual el público descubre el mundo que está más allá de su experiencia inmediata. El mercado relevante no puede ser definido para cada medio, sino que debe abarcar a los periódicos, la radio, la televisión, las revistas, los libros e incluso a las películas, en un todo unitario. En este mercado global, existen fuerzas dominantes o que ejrcen liderazgo y que dan forma a la opinión pública, pero no existe un monopolio.

A negação da existência dos monopólios informativos por parte da doutrina norte-americana tem suas raízes na sua formação liberal, a qual tende a interpretações de liberalidade das ações mercadológicas, vendo nessa situação as grandes corporações da comunicação como forças de mercado e não como hegemonias. Embora se respeite esse posicionamento, a realidade brasileira não se enquadra nessas linhas estrangeiras (havendo estudos nos quais são descritos monopólios informativos no Brasil $^{27}$ ), já que sendo o país um modelo democrático de direito, há uma preocupação com a redução das desigualdades sociais, 
ou seja, a espécie de Estado adotada exige uma postura diferenciada no sentido da igualdade material aos cidadãos, o que, sem dúvida, não se coaduna com a formação de monopólios informativos.

Ademais, além das incompatibilidades contextuais nacionais, inclusive, com o modelo de Estado adotado, a base crítica aos monopólios são os próprios direitos fundamentais, os quais, nessa situação, são ofendidos, primeiramente, conforme já aludido, no sentido de que a adoção desses monopólios ocorre o não cumprimento da missão democrática devido à redução na pluralidade informativa. A segunda possibilidade se dá com o requisito (inserido através da ética ${ }^{28}$ ) da função social, vislumbrado principalmente nos estudos contemporâneos da propriedade, ligando-se de forma simbiótica, impondo uma nova visão, mais flexível ${ }^{29}$, de cunho mais social e coletivo, a qual se incompatibiliza com o pensamento econômico restritivo.

No sentido da última colocação, os monopólios informativos são incompatíveis com a ideia de função social, pois esta visa ponderar interesses privados e públicos para impedir abusos de mercado que firam direitos fundamentais, como as liberdades de expressão, imprensa e informação. Desta forma, pode-se afirmar que estando as atividades informativas compreendidas na órbita de atuação do direito privado, os meios de comunicação contemplam uma função social, decorrente de seu vínculo direto com os direitos fundamentais (tanto no sentido de efetivação quanto de violação) ${ }^{30} \mathrm{e}$, portanto, não podem aceitar ações liberalistas como os monopólios.

Assim, mesmo com temores de abusos de poder, sejam eles privados ou da utilização da imprensa ${ }^{31}$, entende-se que é possível estruturar a atividade econômica com o cumprimento das funções sociais por parte dos meios de comunicação, auferindo assim o cumprimento de suas incumbências, com lucro. Igualmente, estar-se-ia auxiliando na efetivação dos direitos fundamentais, como a liberdade de imprensa, a informação, os direitos de personalidade, ${ }^{32}$ e trilhando ao mesmo tempo um caminho correto ao desenvolvimento democrático. 


\section{CONSIDERAÇÕES FINAIS}

O anunciar resplandecente de novos dias no Brasil apresentou-se a partir da Constituição e da sua proclamação como um Estado Democrático de Direito, pautando-se sobre novos fundamentos, orientados sob a base da dignidade humana, objetivando a modificação não somente do Direito, mas da sociedade brasileira. O combustível para essa nova jornada era especialmente os princípios constitucionais e os direitos fundamentais, estando eles a ofertar uma rota interpretativa e, além da alta carga axiológica, constituindo-se em marcos protetivos dos indivíduos e da coletividade, todos decorrentes do prisma da dignidade humana.

Nesse sentido, buscando a estruturação de uma sociedade equilibrada e justa, o texto constitucional preocupou-se com a proteção das manifestações expressivas dos seres humanos, resguardando tais liberdades a fim de propiciar a interconexão comunicativa como forma de crescimento da personalidade. Por isso, tornou-se inerente ao ideal nacional a efetivação dos direitos à liberdade de expressão, imprensa e informação, os quais empregados por meio dos órgãos comunicativos são capazes de dissipar opiniões, notícias e o conhecimento acerca da realidade e de informações preciosas aos cidadãos.

Há aqui a localização de uma problemática, pois apesar da verificação de um interesse coletivo, este depende dos meios de comunicação, os quais são entes privados, para sua concretização. Dito isto, contribui para um desenvolvimento sócio-democrático o fenômeno constitucionalizador do direito privado, visto que este traz outro enfoque às relações particulares, imperando uma ótica de cunho econômico-social. Entretanto, as forças econômicas, de difícil intervenção, tornam a tarefa de compatibilizar interesses econômicos e sociais uma tarefa complexa.

Com efeito, o surgimento de monopólios informativos é a demonstração de uma realidade alterada, na qual se encontram poderes privados que oprimem facções da sociedade e até mesmo Estados, não significando, contudo, que deva haver uma submissão a essa situação. A resistência contra tais manifestações de poder são necessárias para manutenção das liberdades comunicativas no país, estas representando 
os direitos fundamentais, bem como o próprio caminho vislumbrado para o desenvolvimento brasileiro, o qual deseja compatibilizar questões econômicas e sociais sob o viés democrático.

Diante do exposto, posiciona-se em prol de um desenvolvimento social e democrático diferenciado, alinhavando-se pelas bases constitucionais nas relações privadas, ou seja, contrapondo-se aos monopólios informativos, bem como compactuando com noções como a da função social para alcançar um patamar mais igualitário e solidário e, ao mesmo tempo, mais justo à coletividade nacional.

\section{NOTAS}

1 CANOTILHO, José Joaquim Gomes. Direito constitucional. 7. ed. Coimbra: Almedina, 2004. p. 225. "Perante as experiências históricas da aniquilação do ser humano (inquisição, escravatura, nazismo, stalinismo, polpotismo, genocídios étnicos) a dignidade da pessoa humana como base da República significa, sem transcendências ou metafísicas, o reconhecimento do homo noumenon, ou seja, do indivíduo como limite e fundamento do domínio político da República. Neste sentido, a República é uma organização política que serve ao homem, não é homem que serve aos aparelhos político-organizatórios".

2 SARLET, Ingo Wolfgang. Dignidade da pessoa humana e direitos fundamentais na Constituição Federal de 1988. 5. ed. Porto Alegre: Livraria do Advogado, 2008. p. 83. "Se, por um lado, consideramos que há como discutir - especialmente na nossa ordem constitucional positiva - a afirmação de que todos os direitos e garantias fundamentais encontram seu fundamento direto, imediato e igual na dignidade da pessoa humana, do qual seriam concretizações, constata-se, de outra parte, que os direitos e garantias fundamentais podem - em princípio e ainda que de modo e intensidade variáveis -, ser reconduzidos de alguma forma à noção de dignidade da pessoa humana, já que todos remontam à idéia de proteção e desenvolvimento das pessoas, de todas as pessoas, como bem destaca Jorge Miranda".

3 SARLET, Ingo Wolfgang. Dignidade da pessoa humana e direitos fundamentais na Constituição Federal de 1988. 5. ed. Porto Alegre: Livraria do Advogado, 2008. p. 37. “De qualquer modo, incensurável, isto sim, como teremos oportunidade de demonstrar no próximo segmento, é a permanência da concepção kantiana no sentido de que a dignidade da pessoa humana, esta (pessoa) considerada como fim, e não como meio, repudia toda e qualquer espécie de coisificação e instrumentalização do ser humano". Em igual sentido a posição de, RODRIGUEZ, Javier Llobet. Derechos humanos y justicia penal. Heredia: Poder Judicial, Depto. De Artes Gráficas, 2007. p. 45-46.

4 O autor apresenta diferenciação sobre a liberdade de expressão e as liberdades de imprensa e informação SABAU, José Ramón Pólo. Libertad de expresión y derecho de acesso a los médios de comunicación. Madrid: CEPC, 2002. p. 15.

5 BARROSO, Luís Roberto. Colisão entre liberdade de expressão e direitos de personalidade. Revista latino-americana de estudos constitucionais, São Paulo, n. 5, p. 319, jan./jun. 2005. "Além das expressões liberdade de informação e de expressão, há ainda uma terceira locução que se tornou tradicional no estudo do tema e que igualmente tem assento constitucional, qual seja, a liberdade de imprensa. A expressão designa a liberdade reconhecida (na verdade, conquistada ao longo do tempo) aos meios de comunicação em geral (não apenas impressos, como o termo poderia sugerir) de comunicarem fatos e idéias, envolvendo desse modo, tanto a liberdade de informação como a de expressão".

6 PEREIRA, Guilherme Döring Cunha. Liberdade e responsabilidade dos meios de comunicação. São Paulo: Revista dos Tribunais, 2002. p. 156. “Ora, não é de esquecer-se que o 
As liberdades informativas e a participação privada dos meios de comunicação no processo de desenvolvimento democrático: um paralelo entre os monopólios econômicos e os interesses sociais

erro cometido de boa-fé, no afã de acertar e de avançar e de trazer progresso, tem papel indiscutivelmente positivo, também eticamente. É mais nobre errar por ter tentado algo valioso do que se omitir por medo de sanções ou represálias". Menciona-se também nesse sentido a abordagem de Owen Fiss, o qual traz entendimento semelhante, mas com base em um caso julgado nos Estados Unidos em 1964, pela Suprema Corte. FISS, Owen. La ironía de la libertad de expresión. Barcelona: Gedisa, 1999. p. 72.

7 O autor traz a perspectiva do direito uruguaio, no entanto, analogicamente suas colocações encaixam-se igualmente no sentido de legitimidade do direito à resposta, refutando a mentira veiculada através do uso da liberdade de imprensa. TERRA, Eduardo Héguy. La responsabilidad de los medios de comunicación. Montevideo: Fundación Fontana Minelli, 2001. p. 55. "El derecho de respuesta, polémico en otros países, en el derecho positivo uruguayo se le reconoce a toda persona física o jurídica afectada [...] Como lo expresa la doctrina, la réplica se funda en el derecho a la verdad, pero no porque ella esté contenida en la respuesta, sino porque presentando las dos versiones de los hechos habrá más elementos de juicio que faciliten accender a la verdad". Contribui também ao afastamento da mentira os fundamentos de Kant, com base na dignidade humana, conforme expõe HÄBERLE, Peter. Os problemas da verdade no estado constitucional. Porto Alegre: Sergio Fabris, 2008. p. 64.

8 Art. $5^{\circ}$, IV - é livre a manifestação do pensamento, sendo vedado o anonimato; V - é assegurado o direito de resposta, proporcional ao agravo, além da indenização por dano material, moral ou à imagem; IX - é livre a expressão da atividade intelectual, artística, científica e de comunicação independentemente de censura ou licença; XIV - é assegurado a todos o acesso a informação e resguardado o sigilo da fonte, quando necessário ao exercício profissional.

Art. 220. A manifestação do pensamento, a criação, a expressão e a informação, sob qualquer forma, processo ou veículo não sofrerão qualquer restrição, observando o disposto nesta Constituição. $\S 1^{\circ}$ Nenhuma lei conterá dispositivo que possa constituir embaraço à plena liberdade de informação jornalística em qualquer veículo de comunicação social, observando o disposto no art. $5^{\circ}, I V, V, X$, XIII e XIV. $§ 2^{\circ}$ É vedada toda e qualquer censura de natureza política, ideológica e artística.

9 CASTRO, Carlos Roberto Siqueira. A Constituição aberta e os direitos fundamentais: ensaios sobre o constitucionalismo pós-moderno e comunitário. 2. ed. Rio de Janeiro: Forense, 2010. p. 437. “O direito a informação, que compreende de modo amplo o direito a ser informado e a ter acesso às informações necessárias ou desejadas para formação do conhecimento, constitui por certo, juntamente com o direito à vida, a mais fundamental das prerrogativas humanas, na medida em que o saber determina o entendimento e as opções da consciência, o que distingue os seres inteligentes de todas as demais espécies que exercitam o dom da vida. Trata-se, também, do pré-requisito mais essencial ao regime democrático, sabido que os indivíduos e sobretudo um povo desinformado e destituído da capacidade de crítica para avaliar o processo social e político acham-se proscritos das condições da cidadania que dão impulso aos destinos das nações".

10 MIRAGEM, Bruno. Liberdade de imprensa e proteção da personalidade no direito brasileiro: perspectiva atual e visão de futuro. Revista trimestral de direito civil. Rio de Janeiro: Padma. v. 40, outubro - dezembro, 2009. p. 25. “Entre nós, esse caráter dúplice da liberdade de informação é reconhecida amplamente pela doutrina especializada. Para Castanho de Carvalho, ela divide-se em cinco elementos, quais sejam: faculdade de investigar; dever de informar; direito de informar; direito de ser informado; e faculdade de receber ou não a informação".

11 Apresenta a prestação das informações verdadeiras como um dever inerente ao exercício da liberdade dos meios de comunicação a autora SCHMITT, Rosane Heineck. Direito à informação: liberdade de imprensa x direito à privacidade. In: SARLET, Ingo Wolfgang (Org.). A Constituição concretizada: construindo pontes com o público e o privado. Porto Alegre: Livraria do Advogado, 2000. p. 219.

12 LIMBERGER, Têmis. O direito à intimidade na era da informação: a necessidade de proteção dos dados pessoais. Porto Alegre: Livraria do Advogado, 2007. p. 134. “Assim, 
informação veraz não é sinônimo de informação verdadeira. Somente se exige o dever de diligência, no sentido de que a informação tenha sido contrastada 'segundo os cânones do profissionalismo'. Como a informação veraz não é necessariamente verdadeira, nela 'estão incluídas as informações errôneas sempre que tenham sido objeto de contraste: dever específico de diligência'. Ou seja, o conceito de informação veraz aceita até a comunicação errônea, desde que tenha sido contrastada".

13 BONAVIDES, Paulo. Teoria do estado. 5. ed. São Paulo: Malheiros, 2004. p. 324. “O quadro de legitimação do processo político nacional é deveras complicado, pela herança recebida dos 21 anos de exceção. A ditadura desvalorizou neste País a Constituição, o Congresso e os partidos políticos; humilhou-os e rebaixou-os com a ascensão tecnocrática a todos os níveis de poder, bem como a formação de órgãos paraconstitucionais de decisões - o Conselho Monetário, o Conselho de Desenvolvimento Político e sobretudo o ministério íntimo da Presidência, quais se chamam os ministros da Casa, que desfrutam da privacidade palaciana".

14 Mesmo não sendo o enfoque desejado, registra-se aqui o conhecimento de uma grande quantidade de obras tratando do tema democracia, bem como a existência de espécies diferentes, mas no caso deste estudo o interesse reserva-se a uma visão de sociedade democrática. Mesmo assim, citar-se uma obra que aprofunda essa questão. FERRARI, Vincenzo. Democracia e informação no final do século XX. In: GUIMARÃES, César; JUNIOR, Chico (Org.). Informação e democracia. Rio de Janeiro: EdUERJ, 2000. p. 164.

15 FERRARI, Vincenzo. Democracia e informação no final do século XX. In: GUIMARÃES, César; JUNIOR, Chico (Org.). Informação e democracia. Rio de Janeiro: EdUERJ, 2000. p. 165 -166. “Se democracia significa liberdade e igualdade no gozo de direitos e de oportunidades, parece claro que a informação livre, como acentuado no início, dela constitui fundamento um fundamento essencial [...] Compreende-se assim 'informação' não é somente 'o ato de informar' como diz o vocabulário, mas em geral é parte essencial do processo de formação de conhecimentos, de opiniões e, portanto, da própria personalidade do indivíduo: a parte que age mediante a interação do sujeito com o mundo externo. A falta de informação bloqueia o desenvolvimento da personalidade, tornando-a asfixiada. Outrossim, uma informação unilateral, advinda de uma só fonte, mesmo que quantitativamente rica e qualitativamente sofisticada, direciona a personalidade para canais preestabelecidos, limitando objetivamente a oportunidade de escolha e a capacidade crítica do indivíduo, prejudicando desta forma a sua participação nos processo democráticos. [...] A relação entre democracia e informação é, portanto, biunívoca, de coessencialidade, no sentido de que uma não pode existir sem a outra e o conceito de uma comporta o conceito da outra". Em igual sentido a posição de SOUZA, Sérgio Ricardo de. Controle judicial dos limites constitucionais à liberdade de imprensa. Rio de Janeiro: Lumen Juris, 2008. p. 103 - 104.

16 GUERRA, Sidney Cesar Silva. A liberdade de imprensa e o direito à imagem. 2. ed. Rio de Janeiro: Renovar, 2004. p. 82. "A liberdade de imprensa não é um direito dos profissionais da imprensa mas toda sociedade e, portanto, deve ser protegido por todos nós, tendo em vista que estes direitos, como demonstrado, foram conquistados com muita luta e de forma bastante lenta". De forma semelhantes apresenta-se o pensamento do Tribunal Constituicional Alemão e do autor WEINGARTNER NETO, Jayme. Honra, privacidade e liberdade de imprensa: uma pauta de justificação penal. Porto Alegre: Livraria do Advogado, 2002. p. 85. “O Tribunal Constitucional alemão considera que o bem protegido pela liberdade de imprensa não é apenas a liberdade individual, mas a imprescindibilidade da imprensa livre para a democracia. Segundo a fórmula jurisprudencial, 'na democracia representativa, a imprensa é o órgão de controle e de conexão entre o povo e seus representantes no parlamento e no governo...'".

17 No sentido da aplicação dos direitos fundamentais nas relações interprivadas tem-se as palavras de SILVA, Virgílio Afonso da. A constitucionalização do direito. Os direitos fundamentais nas relações entre particulares. São Paulo: Malheiros, 2005. p. 41-43.

18 SARMENTO, Daniel. Direitos fundamentais e relações privadas. 2 ed. Rio de Janeiro: Lúmen Juris, 2010. p. 76. “Cumpre, por outra banda, destacar que a constitucionalização do Direito Privado não se resume ao acolhimento, em sede constitucional, de matérias que no passado eram versadas no Código Civil. O fenômeno é muito mais amplo, e importa na '[...] releitura do Código Civil e das leis especiais à luz da Constituição Republicana'”. 
As liberdades informativas e a participação privada dos meios de comunicação no processo de desenvolvimento democrático: um paralelo entre os monopólios econômicos e os interesses sociais

19 TEPEDINO, Gustavo. Normas constitucionais e direito civil na construção unitária do ordenamento. In: SOUZA NETO, Cláudio Pereira de; SARMENTO, Daniel (Coord.). A constitucionalização do direito: fundamentos teóricos e aplicações específicas. Rio de Janeiro: Lumen Júris, 2007. p. 310. “Mais de uma década depois, a promulgação do Código Civil de 2002 impôs a reflexão acerca dos paradigmas axiológicos que devem nortear o intérprete na reconstrução dos institutos de direito privado. A este respeito, deve-se observar que o direito civil assistiu ao deslocamento de seus princípios fundamentais do Código Civil para a Constituição. Tal realidade, reduzida por muitos a fenômeno de técnica legislativa, ou mesmo à mera atecnia, revela profunda transformação dogmática, em que a autonomia privada passa a ser remodelada por valores não patrimoniais, de cunho existencial, inseridos na própria noção de ordem pública. Propriedade, empresa, família, relações contratuais, em especial da dignidade da pessoa humana, não mais havendo setores imunes a tal incidência axiológica, espécies de zonas francas para a atuação da autonomia privada. A autonomia privada deixa de configurar um valor em si mesma, e será merecedora de tutela somente se representar, em concreto, a realização de um valor constitucional".

20 Existem diversas propostas inovadoras no campo econômico democrático, inclusive reestruturando as próprias concepções de trabalho e do tempo despendido com as atividades, no caminho para uma existência humana saudável e harmônica com a sociedade e o próprio planeta. Entre elas podem-se mencionar duas obras de ângulos diferentes, a primeira com um enfoque reeducativo econômico-global e a outra numa revisão do desenvolvimento humano no planeta, são elas: DOWBOR, Ladislau. Democracia econômica: alternativas de gestão social. Petrópolis: Vozes, 2008 e SACHS, Ignacy. Caminhos para o desenvolvimento sustentável. 3 ed. Rio de Janeiro: Garamond, 2008.

21 A hodierna relação entre poder político (estatal) e econômico (privado) é apreciada com propriedade por Dowbor, que prega a democratização da economia exatamente por compreender a grande influência e amplitude deste poder privado, inclusive, sobre o poder do Estado. O autor chama atenção para o fato de as sociedades modernas muito se preocuparem com a democracia no âmbito político, mas, contemporaneamente tem-se verificado o surgimento de um amplo poder econômico, de feição privada, e que, portanto, não é submetido aos padrões convencionais de controle. Tal fato pode ser exemplificado pela existência de empresas e grupos econômicos que apresentam orçamentos muito mais elevados que boa parte de países inteiros. Nas palavras do autor: DOWBOR, Ladislau. Democracia econômica: alternativas de gestão social. Petrópolis: Vozes, 2008. p. 54. “O argumento básico, no conjunto, é claro: surge um amplo poder político, mas com cara econômica e, portanto, não submetido a controles políticos, pois seria controlado pelas 'forças do mercado'. Na realidade, não é controlado por força nenhuma".

22 UBILLOS, Juan María Bilbao. ¿En qué medida vinculan a los particulares los derechos fundamentales? In: SARLET, Ingo Wolfgang (Org.). Constituição, direitos fundamentais e direito privado. 3. ed. Porto Alegre: Livraria do Advogado, 2010. p. 220-221. “Frente a esa concepción unidireccional de los derechos de libertad, en el Estado social de derecho se abre paso um nuevo entendimiento de las relaciones Estado-sociedad, que acaba desenmascarando, poniendo al descubierto la ficción que vinculaba el disfrute de la libertad en la esfera social a la simple afirmación del principio de igualdad jurídica. Hoy como ayer la realidad desmiente la existencia de una paridad jurídica en buena parte de las relaciones que establan los sujetos privados. El Derecho privado conoce también el fenómeno de la autoridad, del poder, como capacidad de determinar o condicionar jurídicamente o de facto las decisiones de otros, de influir eficazmente en el comportamiento de otros, de imponer la propia voluntad. Basta con mirar alreddedor y observar atentamente la realidad que nos rodea. Es un hecho fácilmente constatable la progresiva multiplicación de centros de poder privados y la enorme magnitud que han adquirido algunos de ellos. Representan en la actualidad una amenaza nada desdeñable para las libertades individuales. El poder ya no está concentrado en el aparato estatal, está disperso, diseminado en la sociedad. Al fin y al cabo, el fenómeno del poder como expresión de una situación de deisgualdad es indisociable de las relaciones humanas, es inherente a toda organización social". 
23 Ao abordar a temática relativa à verdade, Häberle se depara com problemáticas envolvendo a democracia pluralista e o Estado, bem como aborda questões relativas à imprensa e à informação. HÄBERLE, Peter. Os problemas da verdade no estado constitucional. Porto Alegre: Sergio Fabris, 2008. p. 113. “Em particular, a democracia pluralista do Estado constitucional depara-se diretamente com três áreas problemáticas da questão da verdade: nos conflitos sobre a relação entre <<verdade e maioria >>, no entendimento da formação da opinião pública da sociedade e, como parte disso, na limitação da liberdade de imprensa a favor do interesse de outros valores protegidos e as suas orientações referentes à crônica jornalística $<<$ fidedigna à verdade $>>$ (ao invés da $<<$ mentira mediática $>>$ )". Em sentido complementar menciona-se Marcelo Campos Galuppo e sua construção acerca do pluralismo e da sua formatação no Estado Democrático de Direito. GALUPPO, Marcelo Campos. Hermenêutica constitucional e pluralismo. In: SAMPAIO, José Adércio Leite; CRUZ, Álvaro Ricardo de Souza (Coord.). Hermenêutica e jurisdição constitucional. Belo Horizonte: Del Rey, 2001. p. 61. “É preciso levar em conta, então, que cumprir ou aplicar o direito, no Estado Democrático de Direito, não é cumprir ou aplicar todas as normas jurídicas contemporaneamente, mas apenas aquelas que são adequadas ao contorno fático de uma situação".

24 FERRARI, Vincenzo. Democracia e informação no final do século XX. In: GUIMARÃES, César; JUNIOR, Chico (Org.). Informação e democracia. Rio de Janeiro: EdUERJ, 2000. p. 171. "Tanto o monopólio público, quanto o monopólio privado das fontes informativas é incompatível com a democracia: uma democracia deve impedir ambos com leis antitrust no setor privado e com garantia de gestão pluralista no setor público. [...] Uma democracia é tão sólida quanto mais o poder seja subdividido, fragmentado em uma gama de centros capazes de se controlarem reciprocamente.A multiplicação das fontes de informação é, portanto, funcional à própria democracia". Na mesma linha de pensamento está SILVA, Virgílio Afonso da. A constitucionalização do direito. Os direitos fundamentais nas relações entre particulares. São Paulo: Malheiros, 2005. p. 78. "Para ficar em um exemplo emblemático, é possível, a partir da liberdade de informação, que sempre foi entendida como uma liberdade pública, um direito a não ser obstado pela atividade estatal no exercício da plena busca pela informação - o que, como reflexo implica a exigência de outra abstenção estatal: a vedação de censura - desenvolver uma outra dimensão desse direito: o direito a uma ação estatal, por exemplo, no sentido de garantir, via ação estatal, a pluralidade de fontes de informação e de coibir o monopólio nos meios de comunicação".

25 LANER, Vinicius Ferreira. Comunicação, desenvolvimento e democracia: uma análise crítica da mídia brasileira à luz do direito à informação e à liberdade de imprensa. Santa Cruz do Sul: Edunisc, 2004. p. 25. “Esses monopólios que dominam o mercado da indústria cultural constituem significativos entraves para democratização dos meios de comunicação. A concentração de meios de comunicação permitida no Brasil, com TVs, rádios, jornais e revistas na posse de um mesmo grupo ou mesmo centralizada em uma só pessoa, é uma força anti-democrática, anti-social e inconstitucional". Soma-se a posição contrária aos monopólios informativos, com abuso do poder privado a de UBILLOS, Juan María Bilbao. ¿En qué medida vinculan a los particulares los derechos fundamentales? In: SARLET, Ingo Wolfgang (Org.). Constituição, direitos fundamentais e direito privado. 3 ed. Porto Alegre: Livraria do Advogado, 2010. p. 221.

26 FISS, Owen. La ironía de la libertad de expresión. Barcelona: Gedisa, 1999. p. 74.

27 A obra referida contém um estudo aprofundado sobre o assunto, sendo possível remeter uma passagem da obra apenas para demonstrar o caráter jurídico-crítico da abordagem de LANER, Vinicius Ferreira. Comunicação, desenvolvimento e democracia: uma análise crítica da mídia brasileira à luz do direito à informação e à liberdade de imprensa. Santa Cruz do Sul: Edunisc, 2004. p. 25. “Esses monopólios que dominam o mercado da indústria cultural constituem significativos entraves para democratização dos meios de comunicação. A concentração de meios de comunicação permitida no Brasil, com TVs, rádios, jornais e revistas na posse de um mesmo grupo ou mesmo centralizada em uma só pessoa, é uma força anti-democrática, anti-social e inconstitucional". 
As liberdades informativas e a participação privada dos meios de comunicação no processo de desenvolvimento democrático: um paralelo entre os monopólios econômicos e os interesses sociais

28 VELÁZQUEZ, Victor Hugo Tejerina. Alguns aspectos da função social da propriedade no novo código civil. Revista autônoma de direito privado, Curitiba, n. 1, p. 67, out./ dez. 2006. "Por influência da ética social cristã, a propriedade deve cumprir uma função e um serviço, daí que o proprietário tem não apenas direitos como deveres para com a sociedade, de tal modo que o conteúdo da propriedade há de configurar-se atendendo o interesse público, ou da ordem econômica e financeira $[\ldots . . .]^{\prime \prime}$.

29 MENDES, Gilmar Ferreira. Direitos fundamentais e controle de constitucionalidade: estudos de direitos constitucional. 3 ed. São Paulo: Saraiva, 2009. p. 19. "Inexiste, todavia, um conceito constitucional fixo, estático, de propriedade, afigurando-se, fundamentalmente, legítimas não só as novas definições de conteúdo como a fixação de limites destinados a garantir a sua função social. É que, embora não aberto, o conceito constitucional de propriedade há de ser necessariamente dinâmico".

30 PEREIRA, Guilherme Döring Cunha. Liberdade e responsabilidade dos meios de comunicação. São Paulo: Revista dos Tribunais. 2002. p. 28. “A afirmação de que cabe às empresas uma função social, de que elas têm uma função social inerente à atividade, não é mais algo realmente problemático. A idéia já ganhou foros de cidadania. Não seriam poucos os empresários que a endossariam, mesmo talvez sem saber exatamente o que vem implicado nela".

31 DONNINI, Oduvaldo; DONNINI, Rogério Ferraz. Imprensa livre, dano moral, dano à imagem e sua quantificação à luz do novo código civil. São Paulo: Método, 2002. p. 31. "Imprensa livre e influência direta do poder econômico e financeiro sempre foi uma relação perigosa. O fato de grandes empresas utilizarem-se da imprensa para propagar uma certa imagem que algumas vezes está distante da realidade não é novidade. Para a proteção da sociedade existe legislação eficaz na defesa do consumidor. A grande preocupação é a nova fase dos meios de comunicação em que não apenas são comprados espaços publicitários na mídia falada, escrita e televisiva, mas adquiridos pelas grandes corporações os próprios veículos de comunicação. Nesse caso, investimentos grandiosos são realizados, que tendem a crescer ainda mais com a Internet na denominada indústria da imagem, e essa união entre imprensa e grande empresa (comercial ou industrial) revela-se perigosa, haja vista que interesses comerciais podem distanciar o fato verdadeiro da informação jornalística e, como conseqüência, aniquilar a função social da imprensa e seu compromisso com a veracidade da informação".

32 PEREIRA, Guilherme Döring Cunha. Liberdade e responsabilidade dos meios de comunicação. São Paulo: Revista dos Tribunais. 2002. p. 36-37. “Quanto se disse é de mais fácil percepção, caso se considere em concreto as empresas de comunicação. É patente a influência profundamente positiva na sociedade que pode derivar de um adequado cumprimento da sua atividade material específica. Dar satisfação às necessidades fundamentais de informação, formação, entretenimento etc., não de um determinado indivíduo, mas de toda uma coletividade, é, em si mesmo, e independentemente de qualquer ulterior esforço, uma contribuição decisiva para o bem comum. Algumas das considerações feitas acima seriam até dispensáveis, porquanto fica evidente, à primeira vista, a íntima conexão entre consecução da função social própria dos meios de comunicação e obtenção das metas empresariais de índole mais econômica. Em poucas áreas é também tão patente o dano que se pode produzir na sociedade, quando se sobrepõem ao fim social fins estritamente egoísticos". 


\section{REFERÊNCIAS}

BARROSO, Luís Roberto. Colisão entre liberdade de expressão e direitos de personalidade. Revista latino-americana de estudos constitucionais, São Paulo, n. 5, p. 297-339, jan./jun. 2005.

BONAVIDES, Paulo. Teoria do Estado. 5. ed. São Paulo: Malheiros, 2004.

CANOTILHO, José Joaquim Gomes. Direito constitucional. 7. ed. Coimbra: Almedina, 2004.

CASTRO, Carlos Roberto Siqueira. A Constituição aberta e os direitos fundamentais: ensaios sobre o constitucionalismo pós-moderno e comunitário. 2. ed. Rio de Janeiro: Forense, 2010.

DONNINI, Oduvaldo; DONNINI, Rogério Ferraz. Imprensa livre, dano moral, dano à imagem e sua quantificação à luz do novo código civil. São Paulo: Método, 2002.

DOWBOR, Ladislau. Democracia econômica: alternativas de gestão social. Petrópolis: Vozes, 2008.

FERRARI, Vincenzo. Democracia e informação no final do século XX. In: GUIMARÃES, César; JUNIOR, Chico (Org.). Informação e democracia. Rio de Janeiro: EdUERJ, 2000.

FISS, Owen. La ironía de la libertad de expresión. Barcelona: Gedisa, 1999.

GALUPPO, Marcelo Campos. Hermenêutica constitucional e pluralismo. In: SAMPAIO, José Adércio Leite; CRUZ, Álvaro Ricardo de Souza (Coord.). Hermenêutica e jurisdição constitucional. Belo Horizonte: Del Rey, 2001.

GUERRA, Sidney Cesar Silva. A liberdade de imprensa e o direito à imagem. 2. ed. Rio de Janeiro: Renovar, 2004.

HÄBERLE, Peter. Os problemas da verdade no estado constitucional. Porto Alegre: Sergio Fabris, 2008. 
LANER, Vinicius Ferreira. Comunicação, desenvolvimento e democracia: uma análise crítica da mídia brasileira à luz do direito à informação e à liberdade de imprensa. Santa Cruz do Sul: Edunisc, 2004.

LIMBERGER, Têmis. $\mathrm{O}$ direito à intimidade na era da informação: a necessidade de proteção dos dados pessoais. Porto Alegre: Livraria do Advogado, 2007.

MENDES, Gilmar Ferreira. Direitos fundamentais e controle de constitucionalidade: estudos de direitos constitucional. 3 ed. São Paulo: Saraiva, 2009.

MIRAGEM, Bruno. Liberdade de imprensa e proteção da personalidade no direito brasileiro: perspectiva atual e visão de futuro. Revista trimestral de direito civil, Rio de Janeiro, v. 40, p. 17-69, out./ dez. 2009.

PEREIRA, Guilherme Döring Cunha. Liberdade e responsabilidade dos meios de comunicação. São Paulo: Revista dos Tribunais, 2002.

RODRIGUEZ, Javier Llobet. Derechos humanos y justicia penal. Heredia: poder judicial, Depto. de Artes Gráficas, 2007.

SABAU, José Ramón Pólo. Libertad de expresión y derecho de acesso a los médios de comunicación. Madrid: CEPC, 2002.

SACHS, Ignacy. Caminhos para o desenvolvimento sustentável. 3 ed. Rio de Janeiro: Garamond, 2008.

SARLET, Ingo Wolfgang. Dignidade da pessoa humana e direitos fundamentais na constituição federal de 1988. 5 ed. Porto Alegre: Livraria do Advogado, 2008.

SARMENTO, Daniel. Direitos fundamentais e relações privadas. 2 ed. Rio de Janeiro: Lúmen Juris, 2010.

SCHMITT, Rosane Heineck. Direito à informação - liberdade de imprensa $x$ direito à privacidade. In: SARLET, Ingo Wolfgang (Org.). A constituição concretizada: construindo pontes com o público e o privado. Porto Alegre: Livraria do Advogado, 2000. 
SILVA, Virgílio Afonso da. A constitucionalização do direito. Os direitos fundamentais nas relações entre particulares. São Paulo: Malheiros, 2005.

SOUZA, Sérgio Ricardo de. Controle judicial dos limites constitucionais à liberdade de imprensa. Rio de Janeiro: Lumen Juris, 2008.

TEPEDINO, Gustavo. Normas constitucionais e direito civil na construção unitária do ordenamento. SOUZA NETO, Cláudio Pereira de; SARMENTO, Daniel (Coord.). A constitucionalização do direito: fundamentos teóricos e aplicações específicas. Rio de Janeiro: Lumen Júris, 2007.

TERRA, Eduardo Héguy. La responsabilidad de los medios de comunicación. Montevideo: Fundación Fontana Minelli, 2001.

UBILLOS, Juan María Bilbao. ¿En qué medida vinculan a los particulares los derechos fundamentales? In: SARLET, Ingo Wolfgang (Org.). Constituição, direitos fundamentais e direito privado. 3 ed. Porto Alegre: Livraria do Advogado, 2010.

VELÁZQUEZ, Victor Hugo Tejerina. Alguns aspectos da função social da propriedade no novo código civil. Revista autônoma de direito privado, Curitiba, n. 1, p. 45-86, out./dez. 2006.

WEINGARTNER NETO, Jayme. Honra, privacidade e liberdade de imprensa: uma pauta de justificação penal. Porto Alegre: Livraria do Advogado, 2002.

Artigo recebido em: 29-11-2011

Aprovado em: 03-04-2012 